\title{
Characterizations of Spray Deposited CdTe Thin Film
}

\section{A. D. Kanwate ${ }^{a}$, E. U. Masumdar ${ }^{a}$, V.R. Panse ${ }^{\mathrm{b}}$, Mikael Syvajarvi ${ }^{\mathrm{c}}$ Manmeet Kaur ${ }^{\text {d }}$}

${ }^{a}$ Thin Films and Materials Science Research Laboratory, Department of Physics, Shahu college, Latur- 413512, Maharashtra, India.

${ }^{* b}$ Department of Physics, Late B.S.Arts Prof.N.G.Sci \& A.G.Comm College Sakharkherda, India-443202

${ }^{c}$ Linkoping University, Sweden ALMINICA AB,ICM Research Institute

Research utilisation and innovation capacity

${ }^{d}$ Dept of Applied Physics, Shri Shankaracharya Technical Campus, Bhilai, Chhattisgarh, India,

${ }^{* b}$ Corresponding author email id: vshl.panse@gmail.com

\begin{abstract}
:
The spray pyrolysis is promising technique for deposition of CdTe thin film. We deposited CdTe thin film on glass substrate by homemade spray pyrolysis technique at substrate temperature $300^{\circ} \mathrm{C}$. The CdTe thin film was characterized through Field scanning electron microscopy (FSEM), Energy dispersive X-ray analysis (EDAX), Uv-Visible spectroscopy. The SEM micrograph shows the film was uniform coverage, large number of densely packed grain whosesizes ranging from $474 \mathrm{~nm}$ to $1.64 \mu \mathrm{m}$. From EDAX analysis conform that the presenceof $\mathrm{Cd}$ and Te in prepared film with elemental stoichiometry of $\mathrm{Cd}$ and Se was $50.28 \%$ and $49.72 \%$ respectively. The optical absorption coefficient of the film of order of $10^{6}$ and band gap of the film $1.45 \mathrm{eV}$.
\end{abstract}

Keywords: Thin Film, Morphological, Compositional, Optical

\section{Introduction:}

Theoretically, Cadmium Telluride (CdTe) solar cell technology can improve on the production costs and conversion efficiency of conventional silicon solar cell technology. This was possible due to optimal band gap energy (about $1.4 \mathrm{eV}$ ) for huge light absorptioncapability, solar energy absorption and small cost requirements for production of commercial solar cell [1, 2].S.D. Gunjal et. alhave deposited CdTe thin film on sodalime glass substrate by homemade spray pyrolysis technique at temperature $350^{\circ} \mathrm{C}$. From XRD pattern revealed that, film was cubic crystal structure having crystalline size $32 \mathrm{~nm}$. The SEM micrograph shows a spherical granules with average size of $0.25 \mu \mathrm{m}$. The thickness of the film was found to be $3.2 \mu \mathrm{m}$. In optical study calculated absorbance and band gap of the film and found that 0.94 and $1.44 \mathrm{eV}$ respectively [3]. V.V. Ison et. al have deposited CdTe film on glass substrate by spray pyrolysis techniques with substrate temperature $350^{\circ} \mathrm{C}$. The XRD pattern of CdTe thin film at different ambient condition shows a formation of oxides such as 
$\mathrm{CdTeO}_{3}, \mathrm{TeO}_{2}$ and $\mathrm{Te}$. These oxides removed from $\mathrm{CdTe}$ thin film by adjusting the amount of oxygen in the spray [4].V. M. Nikale et.alinvestigated CdTe thin films have prepared by using spray pyrolysis. The XRD analysis shows the film has polycrystalline nature having cubic structure with strong (111) orientation. Micrographs reveal that grains were uniformly distributed over the surface .The EDAX study shows there was a stoichiometric 1:1 Cd \& Te ratio. The optical absorption shows the presence of direct transition with band gap energy of $1.5 \mathrm{eV}$ [5].Huizhen Yao et.al have been investigated properties of CdTe thin films on Ni foil substrate by screen printing and then film sintered in a nitrogen atmosphere. Furthermore, studied effect of sintering temperature on CdTe thin films. From XRD pattern revealed that the CdTe thin film exhibits cubic crystal structure. From Uv-visible spectra of CdTe thin films revealed that, there was a large absorption in range of $600-900 \mathrm{~nm}$, with the raising sintering temperature, the absorption bands exhibit a constant red-shift. The optical bandgap of the films were found that $1.472 \mathrm{eV}, 1.470 \mathrm{eV}, 1.465 \mathrm{eV}$ and $1.440 \mathrm{eV}$ for films fabricated at $450^{\circ} \mathrm{C}, 500^{\circ} \mathrm{C}, 550^{\circ} \mathrm{C}, 600^{\circ} \mathrm{Crespectively} \mathrm{[6].Laxman} \mathrm{Gouda} \mathrm{et.alhave} \mathrm{been} \mathrm{deposited}$ CdTe thin film on glass and ITO coated glass substrate by using chemical bath deposition with variations in composition of the solution. From XRD pattern revealed that, film exhibit cubic crystal structure with lattice constant $6.4424 \mathrm{~A}^{0}$. The optical studies in the UV-Visible radiation range show that the band gap varies from about $1.26 \mathrm{eV}$ to over $1.8 \mathrm{eV}$ depending on the composition of the film [7].Jun Wang et.alhave been deposited CdTe thin film on $\mathrm{Ni}$ foils by using two-step electrode position method. From SEM images they observed that, film contains some raised particles in one-step CdTe deposition while no raised particles were observed for two-step CdTe thin films, indicating that the smooth surface and dense structure were achieved by two-step electrode position. From Uv-Visible spectra observed that, absorption band of the one-step film yields an onset near $400 \mathrm{~nm}$ and an absorption peak at about $650 \mathrm{~nm}$ [8].

In the present paper deals with synthesis of CdTe thin film by simple and low cost homemade spray pyrolysis techniques onto glass substrate. Further film characterized through Field scanning electron microscopy (FSEM), Energy dispersive X-ray analysis (EDAX), UvVisible spectroscopy.

\section{Experimental Details:}

The spray pyrolysis an easy and inexpensive technique conformable for the manufacture of large area thin films. A main advantage of this technique is that, the properties of the thin films can easily change by varying the deposition conditions.

The CdTe thin film was prepared on glass substrate using homemade spray pyrolysis technique at room temperature $300^{\circ} \mathrm{C}$. Before the deposition the substrates were cleaned with freshly prepared chromic acid, followed by labolene solution and double distilled water. Before the deposition substrates were ultrasonically cleaned for $10 \mathrm{~min}$. For deposition the precursor solution consist of $0.025 \mathrm{M}$ Cadmium Chloride $\left(\mathrm{CdCl}_{2} . \mathrm{H}_{2} \mathrm{O}\right)$ was dissolved in $15 \mathrm{ml}$ double distilled water complexed with two droplets of TEA to release $\mathrm{Cd}^{+}$ions and $0.025 \mathrm{M}$ Selenium dioxides $\left(\mathrm{SeO}_{2}\right)$ dissolved in $7.5 \mathrm{ml}$ of double distilled water complexed by using $7.5 \mathrm{ml}$ aqueous ammonia $\left(25 \% \mathrm{NH}_{4} \mathrm{OH}\right)$ to obtained $\mathrm{pH} \sim 11.5$. Finally these two solutions were mixed together and sprayed by pressurized atmospheric air through a nozzle onto 
preheated glass substrate. The spray rate of the solution was maintained at $2 \mathrm{ml} / \mathrm{min}$. During deposition, substrate was kept $22 \mathrm{~cm}$ apart from nozzle. These spray deposited filmwas strong, mechanically hard, pin hole free. The deposited CdTe thin film wasblack in color.

The gravimetric weight by difference method was used for measuring the thickness of film by using sensitive microbalance. The surface morphology of the film was observed using scanning electron microscope (JOEL-JSM 5600 operating at accelerating voltage of 15 and $200 \mathrm{kV}$ ). Elemental compositions of the film was studied by an Energy dispersive X-ray spectrometer (Bruker EDAX, XFlash6130). Optical absorptions and band of the film was recorded by UV-visible spectrophotometer (Shimadzu 2450).

\section{Result and Discussion:}

\subsection{Thickness Measurements}

The thickness of the deposited films was determined by gravimetric method using the relation [9];

$$
\mathrm{t}=\frac{\Delta \mathrm{m}}{\mathrm{l} \times \mathrm{b} \times \rho}
$$

Where $\Delta m$ is weight difference between before and after the deposition of substrate, $l$ is length of substrate, $b$ is breadth of substrate; $\rho$ is density of CdTe material. The films thickness was found to be $446 \mathrm{~nm}$. The estimated value of thickness is small as compared to previous reported value $[3,4]$.

\subsection{Scanning Electron Microscopy :}

The scanning electron microscopy is used to determine the surface morphology of the deposited CdTe thin film. The micrograph of deposited film as shown in Fig.1 it is observed that, the film was uniform coverage, large number of densely packed cubic crystalline grain whose sizes ranging from $474 \mathrm{~nm}$ to $1.64 \mu \mathrm{m}$. Thus there was not agreement with grain sizes calculated from SEM and XRD. This may be due to two or more grains fusing together to form the cluster type of structure $[10,11]$. 


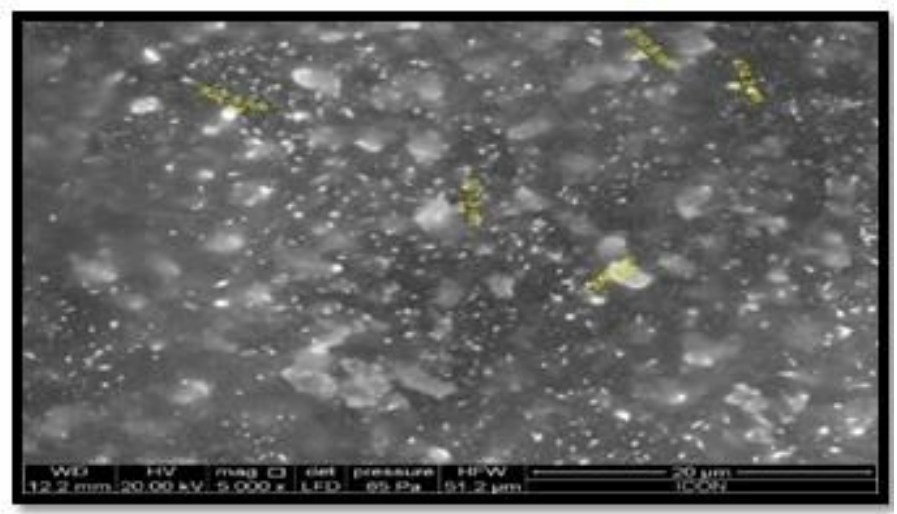

Fig.1: SEM image of deposited CdTe thin film

\subsection{Energy Dissipative X-ray analysis (EDAX):}

The EDAX techniques was used to determine elemental analysis of deposited CdTe thin film. Fig. 2 shows EDAX pattern of CdTe thin film deposited by spray at substrate temperature $300^{\circ} \mathrm{C}$. The presence of well-defined peaks related to $\mathrm{Cd}$ and $\mathrm{Te}$ confirms the successful preparation of CdTe films. . From EDAX analysis conform that the presence of $\mathrm{Cd}$ and $\mathrm{Te}$ in prepared film with elemental stoichiometry of $\mathrm{Cd}$ and $\mathrm{Se}$ was $50.28 \%$ and $49.72 \%$ respectively. It is close to $1: 1$ for prepared $\mathrm{CdTe}$ film. The average weight and atomic percentage of $\mathrm{Cd}$ and $\mathrm{Te}$ is shown in table1.

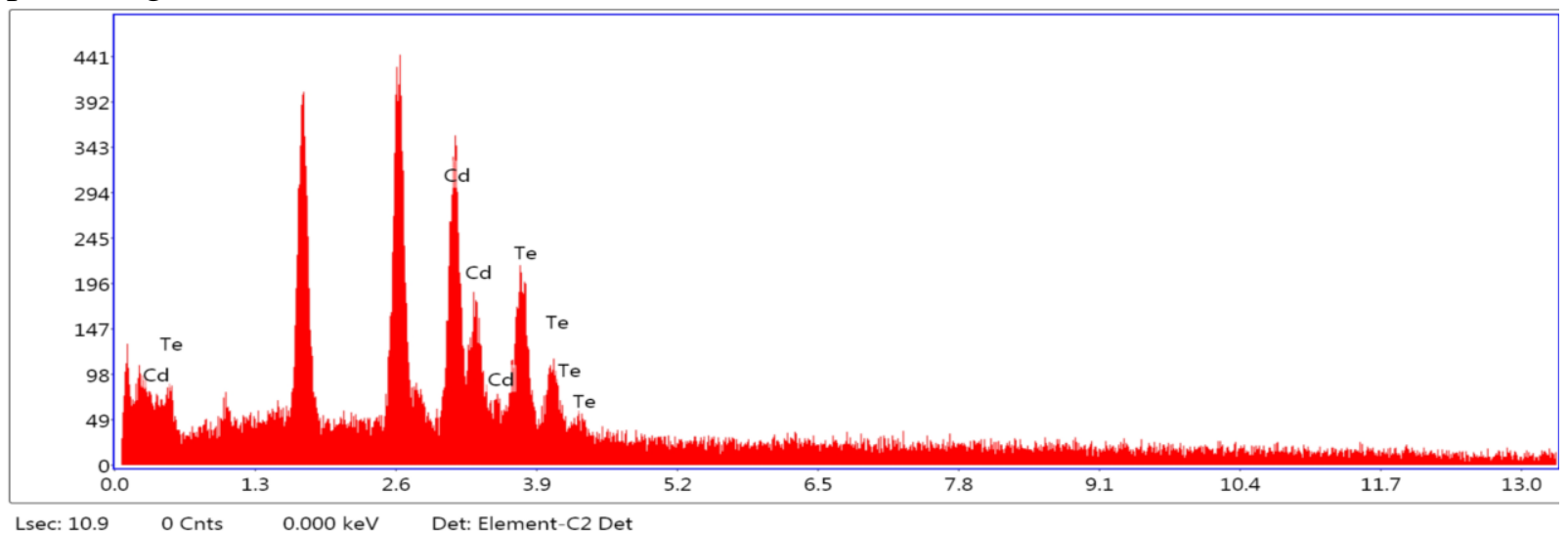

Fig.2: EDAX image of CdTe thin film

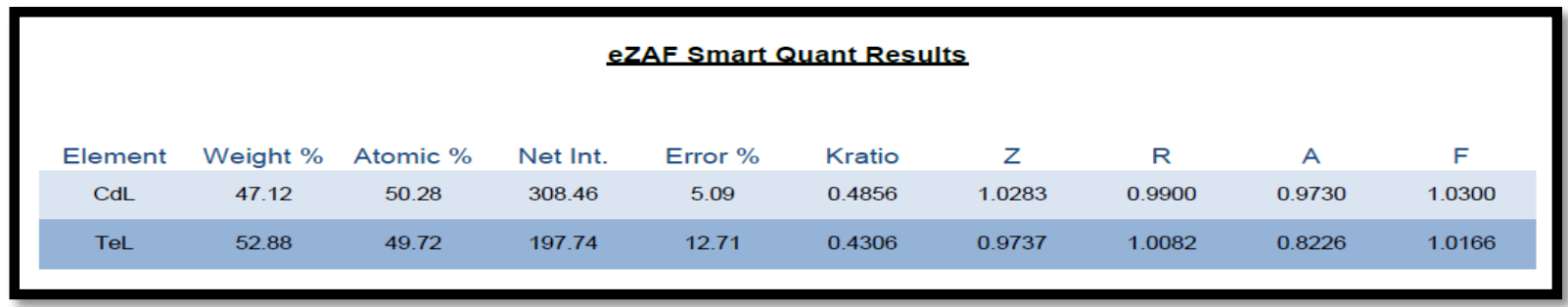

Table-1: Compositional Analysis CdTe thin film

\subsection{Uv-Visible Optical Spectroscopy:}

Fig.3 shows the optical absorption spectra of CdTe thin film recorded in the range 400 to $1100 \mathrm{~nm}$ by UV-vis spectroscopy. The absorption spectra revels the decrease in absorbance with increase in wavelength near the band edge in the range 400-700 $\mathrm{nm}$. The optical 
absorbance was highly sensitive to the distribution of grains and their height variation on the surface of the layers which indicated semiconducting nature of films [20].In the strong absorption region, optical absorption coefficient was estimated by using Beer-Lambert equation [21];

$\alpha=\frac{1}{t} \ln \left(\frac{1}{T}\right)$.

Where $\mathrm{t}$ is the film thickness and $\mathrm{T}$ is transmittance of the film. The value of absorption coefficient is order of $10^{6}$, which is decrease with increase in wavelength. It is good agreement with earlier report [22]. The optical band gap was calculated by assuming a direct transition using Tauc plot given by equation [21];

$\alpha \mathrm{h} v=\mathrm{A}\left(\mathrm{h} v-\mathrm{E}_{\mathrm{g}}\right)^{2}$

Where, $\alpha$-absorption coefficient, hv-incident photon energy, $\mathrm{E}_{\mathrm{g}}$-optical band gap energy. From the linear fit of the plot $(\alpha h v)^{2}$ versus photon energy (E) as shown in fig.4, we estimate the value of $1.45 \mathrm{eV}$. The value of bandgap obtained agrees with the previously results [23, 24].

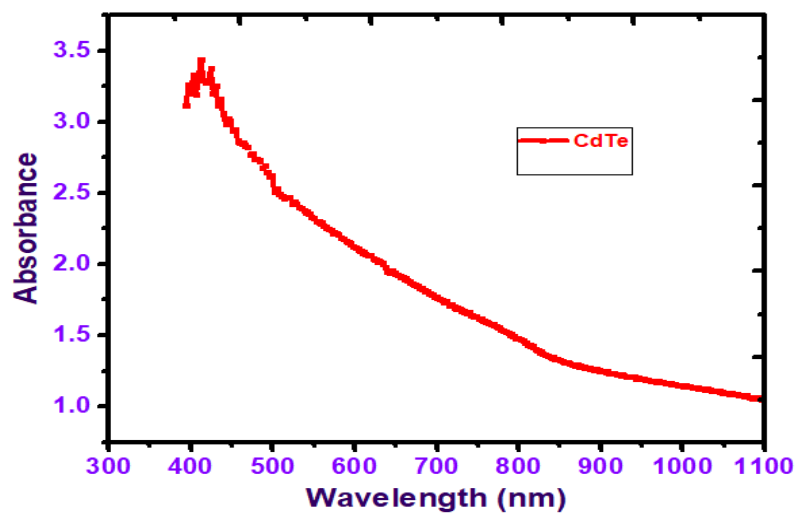

Fig.3:shows the optical absorption spectra of CdTe thin film

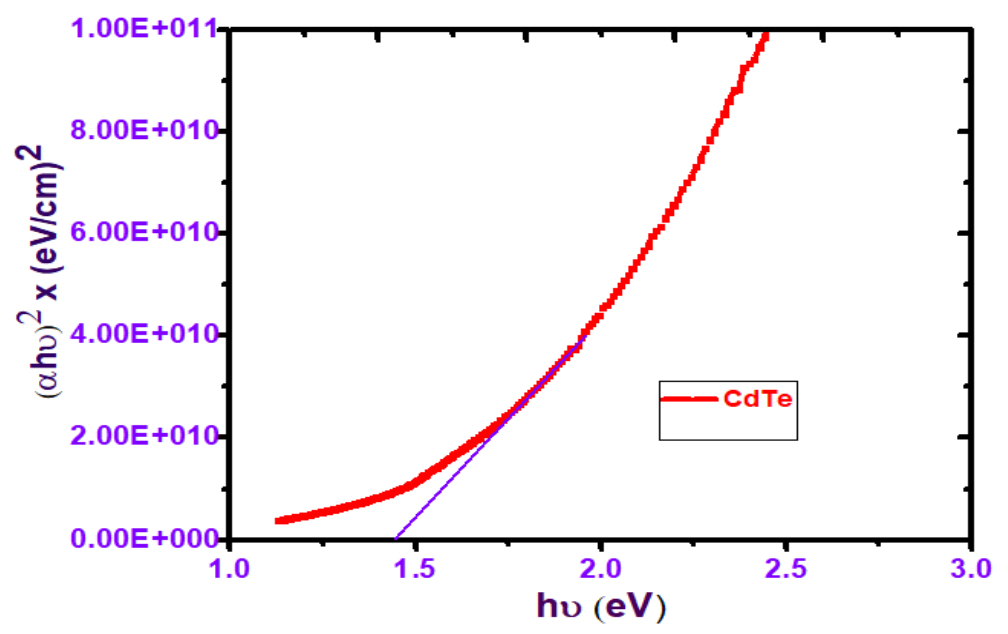

Fig.4: Energy band gap spectra of CdTe thin film

\section{Conclusion:}

The CdTe thin film deposited by homemade spray pyrolysis technique at substrate temperature $300^{\circ} \mathrm{C}$ result as fallows: 
i) The thickness of the deposited CdTe thin film was found that $446 \mathrm{~nm}$.

ii) From the SEM micrograph shows the film was uniform coverage, large number of densely packed grain whose sizes ranging from $474 \mathrm{~nm}$ to $1.64 \mu \mathrm{m}$.

iii) From EDAX analysis conform that the presence of $\mathrm{Cd}$ and $\mathrm{Te}$ in prepared film with elemental stoichiometry of $\mathrm{Cd}$ and Se was $50.28 \%$ and $49.72 \%$ respectively.

iv) The optical absorption coefficient of the film of order of $10^{6}$ and band gap of the film $1.45 \mathrm{eV}$.

From this result, homemade spray pyrolysized deposited CdSe film is suitable for various applications such as photosensitive device includes hetero junction solar cells by avoiding use of $\mathrm{Si}$, photovoltaic cell, thin film transistors, sensors etc.

\section{Acknowledgement}

One of the authors A.D. Kanwate is grateful to the CSIR, New Delhi, India for the financial assistance through the Junior Research Fellowship (File No. 08/595(0002)/2015-EMR-I).

\section{References:}

1) Youn-Ok Choia, Nam-Hoon Kimb, Ju-Sun Parka, Woo-Sun Lee, Materials Science and Engineering B 171 (2010) 73-78.

2) Subhash Chander, M.S.Dhaka, Materials Science in Semiconductor Processing 40 (2015) 708-712.

3) S.D. Gunjal, Y.B. Khollam, S.R. Jadkar, T. Shripathi, V.G. Sathe, P.N. Shelke, M.G. Takwale, K.C. Mohite, Solar Energy 106 (2014) 56-62.

4) V.V. Ison, A. Ranga Rao, V. Dutta, Solid State Sciences 11 (2009) 2003-2007.

5) V. M. Nikale, S. S. Shinde, C. H. Bhosale, and K.Y. Rajpure, Vol. 32, No. 3 Journal of Semiconductors March 2011.

6) Huizhen Yao, Jinwen Ma, Yannan Mu, Shi Su, Pin Lv, Xiaoling Zhang, Liying Zhou, Xue Li, Li Liu, Wuyou Fu, Haibin Yang, Journal of Alloys and Compounds 634 (2015) 19-23.

7) Laxman Gouda, Yelameli Ramesh Aniruddha, Sheela K. Ramasesha, Journal of Modern Physics, 2012, 3, 1870-1877.

8) Jun Wang, Qian Li, Yannan Mu, Suyu Li, Lihua Yang, Pin Lv, Shi Su, Tie Liu, Wuyou Fu ,Haibin Yang, Journal of Alloys and Compounds 636 (2015) 97-101.

9) P. Saha, J. Ganguli, N. Sharma, Chemical Science Transactions, ISSN: 2278-3458 2016, 5(3), 657-660.

10) N. Samarth, H. Luo, J.K. Furdyna, S.B. Qadri, Y.R. Lee, A.K. Ramdas, N. Otsuka, Appl. Phys. Lett. 2680 (1989) 54.

11) R. Wahab, G. Ansari, Y. Kim, H. Seo, G. Kim, G. Khang, et al., Mater. Res. Bull. 42, (2007), 1640-8.

12) S. Mahato, A.K. Kar, J. Elec. Che. 742, (2015), 23-29.

13) S. D. Gunjal, Y. B. Khollam, M.T. Sarode, S.A. Arote, P.N. Shelke, K. C. Mohite, IJCPS ISSN: 2319-6602, Vol. 3 Special Issue - NCETNN Dec-2014.

14) Jun Wang, Qian Li, Yannan Mu, Suyu Li, Lihua Yang, Pin Lv, Shi Su, Tie Liu, Wuyou Fu,Haibin Yang, Journal of Alloys and Compounds 636 (2015) 97-101. 
15) S.L. Rugen-Hankey, A.J.Clayton, V.Barrioz, G.Kartopu, S.J.C.Irvine, J.D. McGettrick, D.Hammond, Solar Energy Materials \& Solar Cells 136 (2015) 213-217.

16) Youn-Ok Choia, Nam-Hoon Kimb, Ju-Sun Parka, Woo-Sun Lee, Materials Science and Engineering B 171 (2010) 73-78.

17) Han Jun-feng, Xiao Liu, Cha Li-mei, Jonathan Hamon, M.P. Besland, Materials Science in Semiconductor Processing 40 (2015) 402-406.

18) Subhash Chander, M.S.Dhaka, Materials Science in Semiconductor Processing 40 (2015) 708-712.

19) Subhash Chander, M.S.Dhaka, Physica E 73 (2015) 35-39.

20) S. Lalitha, R.Sathyamoorthy, S.Senthilarasu, A.Subbarayan, K.Natarajan, Sol. Energy Mater. Sol. Cells 82 (2004) 187-199.

21) J. Tauc and A. Menth, "States in the Gap," Journal of Non-Crystalline Solids, Vol. 810, 1972, pp. 569-585.

22) Pengchen Hu, Bing Li, Lianghuan Feng, Judy Wu, Haibo Jiang, Huimin Yang, Xinju Xiao, Surface \& Coatings Technology 213 (2012) 84-89.

23) Shui-Ping Liu, Jia-Jia Fu, Meng-Juan Li, Lin Lin, Xiao-Qiang Li, Ming-Qiao Ge, Chinese Chemical Letters 25 (2014) 933-936.

24) Yanni Huang, Jianjun Liu, Yingchun Yu, Shengli Zuo, Journal of Alloys and Compounds 647 (2015) 578- 584.

25) Juan-Juan Peng, Shao-Pu Liu, Lei Wang, You-Qiu He, Spectrochimica Acta Part A 75 (2010) 1571-1576.

26) Magdalena Osiala, Justyna Widerab, Krystyna Jackowska, Electrochimica Acta 122 (2014) 275- 281.

27) Seungju Chun, Seunghun Lee, Younghun Jung, Jong Seong Bae, Jihyun Kim, Donghwan Kim, Current Applied Physics 13 (2013) 211-216.

28) K.Vamsi Krishna, V.Dutta, P.D.Paulson, Thin Solid Films 444 (2003) 17-22.

29) Sukhvir Singh, Rajeev Kumar, K.N. Sood, Thin Solid Films 519 (2010) 1078-1081.

30) Xavier Mathew, P.J. Sebastian, Solar Energy Materials \& Solar Cells 59 (1999) 8598.

31) E.R. Shaaban, N. Afify, A. El-Taher, Journal of Alloys and Compounds 482 (2009) 400-404.

32) A.V. Kokate, M.R. Asabe, P.P. Hankare, B.K. Chougule, Journal of Physics and Chemistry of Solids 68 (2007) 53-58.

33) A.A. Al-Ghamdi, Shamshad A.Khan, A.Nagat, M.S.Abd El-Sadek, Optics \& Laser Technology 42 (2010) 1181-1186.

34) V. Plotnikov, X. Liu, N. Paudel, D. Kwon, K.A. Wieland, A.D. Compaan, Thin Solid Films 519 (2011) 7134-7137.

35) J. Fritsche, S. Gunst, E. Golusda, M.C. Lejard, A. Thißen, T. Mayer, A. Klein, R. Wendt, R. Gegenwart, D. Bonnet, W. Jaegermann, Thin Solid Films 387 (2001) 161-164

36) T. Okamoto, A. Yamada, M. Konagai, Thin Solid Films 387 (2001) 6-10.

37) Alessio Bosio, Daniele Menossi, Samantha Mazzamuto, Nicola Romeo, Thin Solid Films 519 (2011) 7522-7525. 
38) E. Campos-González, F.de Moure-Flores, L.E.Ramírez-Velázquez, K. CasallasMoreno, A.Guillén-Cervantes, J.Santoyo-Salazar, G. Contreras-Puente, O.Zelaya-Angel, Materials Science in Semiconductor Processing 35 (2015) 144-148.

39) R. Kavitha, K. Sakthive, Superlattices and Microstructures 86 (2015) 51-61.

40) S. Shanmugan, S. Balaji, D. Mutharasu, Materials Letters 63 (2009) 1189-1191.

41) Nazar Abbas Shah, Abid Ali, Asghari Maqsood, Journal of Non-Crystalline Solids 355 (2009) 1474-1478.

42) C.S. Park, Y.-S. Shin, J.Y. Son, Y. Shonc, T.W. Kang, Y.D. Park, Solid State Communications 150 (2010) 2131-2133

43) Theodore Ganetsos, Eduard Belas, Bill Kotsos, Procedia Engineering 25 (2011) 354 $-357$.

44) M.A. Islam, M.S. Hossain, M.M. Aliyu, M.R. Karim, T. Razykov, K. Sopian, N. Amin, Thin Solid Films 546 (2013) 367-374.

45) M. T. Dejpasand, H. Rezagholipour Dizaji, M. H. Ehsani, Procedia Materials Science $11(2015) 114-118$.

46) G.H. Tariq, M. Anis-ur-Rehman, Materials Science in Semiconductor Processing 30 (2015) 665-671. 